\title{
Nietzsche e Quine: da naturalização da estética à epistemologia naturalizada
}

\author{
Fernando R. de M. Barros*
}

Resumo: Longe de pretender esgotar possíveis semelhanças entre Nietzsche e Quine, o texto que se segue tenciona mostrar, mediante comparações paradigmáticas e admissíveis convergências metodológicas, como ambos os autores, lançando mão de hipóteses naturalistas para interpretar o conhecimento e a estética, respectivamente, tornam possível pensar num naturalismo menos confinante e mais inventivo, livre dos prejuízos do cientificismo e mais condizente com a sensibilidade artística em geral.

Palavras-chave: Nietzsche, Quine, estética, conhecimento, superveniência, naturalismo.

\footnotetext{
* Professor Associado de Filosofia na Universidade Federal do Ceará, Fortaleza, CE, Brasil. ORCID https://orcid.org/0000-0002-1045-4570

Correio eletrônico: frbarros76@gmail.com
} 
Nietzsche e Quine: da naturalização da estética à epistemologia...

Em seu texto "Sobre o que há", ao comentar a teoria endossada por um suposto sr. Wyman, personagem empenhada em dissolver "a boa e velha palavra existir", Quine comenta: "O universo superpopuloso do sr. $Y$ é, em muitos sentidos, desagradável. Ele ofende o senso estético dos que, como nós, apreciam paisagens desertas." Para resumir bastante, o sr. Wyman é um daqueles defensores do possível não realizado, que separa "existência" de "subsistência" e, por esse trilho, subtrai a Pégaso sua atualidade, mas não sua "realidade". Pouco importa que não nos seja facultado conhecer a "real" textura da crina de Pégaso, cuja condição ontológica sempre nos parecerá, afinal de contas, mais rarefeita do que a de nosso próprio cabelo. $\mathrm{O}$ mais importante, para o ontólogo dos possíveis, é expandir modal e reflexivamente a noção de possibilidade contida, ab ovo, na chamada "barba de Platão" - isto é, na doutrina segundo a qual o não-ser deve, em rigor, ser, pois, caso contrário, "o que é aquilo que não há?"2 -, de sorte a neutralizar, com isso, ao menos dois impasses existenciais trazidos com a afirmação do cavalo alado, a saber: a sentença existencial singular "Pégaso existe"; e, além disso, a sentença geral "há cavalos alados". Até onde nos é dado perceber, é certo que nem cavalos alados em geral nem Pégaso em particular estão a pastar em nosso quintal. Mas é certo ainda, como bem lembra Maria E. Reicher, que "de uma sentença verdadeira só podem seguir-se sentenças logicamente verdadeiras. Não é possível, pois, que 'Pégaso é um cavalo alado' seja verdadeiro e, ao mesmo tempo, cavalos alados em geral e Pegasus em particular não existam." ${ }^{3}$ E que não me venham com operadores teóricos próprios aos contos da carochinha, talvez também se queixasse, aqui, o nosso sr. Wyman, confrontando àqueles

1 Quine, 2011, p.15.

2 Quine, 2011, p. 12.

3 Maria E Reicher, 2005, p. 123.

Cad. Nietzsche, Guarulhos/Porto Seguro, v.40, n.2, p. 146-169, maio/agosto, 2019. 
Barros, F. R. M.

que insistissem em dizer "era uma vez" ou "segundo uma lenda, Pégaso foi um cavalo alado etc." Tal expediente não se aplicaria a contento a objetos fictícios mitologicamente tipificados, simplesmente porque, "conforme a história relevante [a mitologia], Pégaso não é uma figura mitológica, mas uma criatura real de carne e osso."4 Aliás, mesmo se substituíssemos Pégaso por algo que não pudesse ser admitido sequer como um possível não realizado - pela "cúpula redonda quadrada do Berkeley College", tal como nos sugere, por exemplo, o próprio Quine no aludido ensaio ${ }^{5}$-, ainda assim, do alto de sua esperteza, o sr. Wyman acreditaria tratar-se de um contrassenso afirmar que a cúpula redonda quadrada não é. Ele afirmaria apenas, apelando à antiga ideia da falta de sentido das contradições, "a expressão 'cúpula redonda quadrada' não tem sentido." ${ }^{\circ}$ Ora, é justamente a essa orientação filosófica, para voltar a nossa citação inicial, que Quine atribui um juízo estético, nela reconhecendo uma qualidade a um só tempo evocativa e condenatória. Que se leia, uma vez mais, a lapidar passagem: "O universo superpopuloso do sr. $Y$ é, em muitos sentidos, desagradável. Ele ofende o senso estético dos que, como nós, apreciam paisagens desertas."7

Isso de reconhecer ou atribuir qualidades estéticas a teses filosóficas não é algo novo. Inclusive, é precisamente esse o caminho entrevisto por Hume, por exemplo, para transferir, ao estético, a cidadania epistemológica até então concedida exclusivamente ao lógico. "A beleza", dirá o célebre autor d'O padrão do gosto, "não é

\footnotetext{
4. Maria E Reicher, 2005, p. 123.

5 "Ainda mais, todo o luxo exuberante do universo de possíveis do sr. Y parece se reduzir a nada se fizermos uma pequena modificação no exemplo e falarmos não de Pégaso, mas de cúpula redonda quadrada do Brekeley College. Se, a menos que Pégaso fosse, seria um contrassenso dizer que Pégaso não é, então, pelo mesmo motivo, seria um contrassenso dizer que a cúpula redonda quadrada do Berkeley College não é, a menos que ela fosse. Mas, diferentemente de Pégaso, a cúpula redonda quadrada do Berkeley College não pode ser admitida nem mesmo como um possível não realizado." (Quine, 2011, p.16).
}

6 Id Quine, 2011, 16.

7 Quine, 2011, p. 15.

148 | Cad. Nietzsche, Guarulhos/Porto Seguro, v.40, n.2, p. 146-169, maio/agosto, 2019. 
Nietzsche e Quine: da naturalização da estética à epistemologia...

uma qualidade das próprias coisas; ela existe apenas no espírito que as contempla, e cada espírito percebe uma beleza diferente." ${ }^{\prime 8}$ Eis por que tentar descerrar as leis que estruturam a beleza "objetiva" seria, para Hume, tão inútil quanto procurar determinar uma doçura real ou um amargor real, haja vista que, conforme as "disposição dos órgãos corporais, o mesmo objeto tanto pode ser doce como amargo." ${ }^{\circ 9} \mathrm{Ou}$ seja: de uma época a outra, de um indivíduo a outro, modifica-se o critério que se nos oferece à apreciação estética. Do modo como despertam e se conformam as nossas inclinações, sempre assimiláveis a pletora de novos caprichos e contextos, resultam juízos diferentes acerca da beleza. Mas, cumpre frisar que essa mesma relatividade, ínsita às formas variáveis de seleção e cultivo do gosto, não implicará, ao esteta, as representações decisórias que intercedem sempre que se trata de descrever as determinações lógicas dos objetos. Mesmo que do ponto de vista teórico-especulativo seja possível reconhecer um critério seguro e uma convexidade discursiva mais coesa para a ciência e, inversamente, denegá-los ao indelineável âmbito do sentimento, notamos que, na prática, a questão é "muito mais difícil de decidir no primeiro caso que no último." ${ }^{10}$ Movidos por uma consciência que se absorve nas esperanças emancipatórias do progresso histórico da razão, os sistemas filosóficos se autoconsumiriam, substituindo uns aos outros na ânsia de fundar e refundar o conhecimento de cunho objetivista, ao passo que as obras de arte, por não se mostrarem avessas às indecisões e contradições, resistiriam paradoxalmente com mais firmeza ao crivo da história e da média empírica imposta pelos séculos. Ecoando essa ideia, Hume adverte-nos: "ARISTÓTELES, PLATÃO, EPICURO e DESCARTES puderam ceder o lugar uns aos outros, sucessivamente, mas TERÊNCIO e VIRGÍLIO continuam a exercer um domínio universal e incontestado sobre o espírito dos

8 David Hume, 2012, p. 95.

9 David Hume, 2012, p. 95.

10 David Hume, 2012, p. 107.

Cad. Nietzsche, Guarulhos/Porto Seguro, v.40, n.2, p. 146-169, maio/agosto, 2019. 
homens. A filosofia abstrata de CÍCERO perdeu o seu prestígio, mas a veemência de sua oratória continua sendo objeto da nossa admiração."

Mas, a vantagem do âmbito estético frente ao lógico não estaria apenas no fato de o primeiro se deixar aderir, sem aguda corrosão interna, a aspectos mais heteróclitos e heterogêneos da efetividade, revelando-se, desse modo, supostamente mais protegido, ou, quando não, imune a possíveis efeitos disruptivos do relativismo, mas porque exigiria, em termos doutrinais, muito menos do que o segundo. E, a bem dizer, nos quadros da epistemologia naturalizada de Quine, à luz da qual não deveria haver uma distinção rigorosa entre ciência natural e teoria do conhecimento, no sentido em que a epistemologia pudesse se jactar em se considerar, num exílio cósmico valorativamente neutro, como o sentido do progresso histórico das ciências, ${ }^{12}$ a diferença entre o estético e o lógico também teria de ser redimensionada, e, no limite, metodologicamente abandonada. Afinal, se outrora, no antigo contexto epistemológico, hipóteses lógico-positivistas de reconstrução do mundo tinham primazia frente à profusão multifária de abordagens de expressão sensualista, haja vista que "buscávamos justificar nosso conhecimento do mundo externo por meio de uma reconstrução racional," "13 doravante, uma vez abandonada essa mesma tentativa de justificação, o "estar consciente deixou de ser necessário", ${ }^{14}$ de sorte que o que deve contar como observação "pode agora ser

11 David Hume, 2012., p. 107.

12 Cf., a esse propósito, a exemplar passagem contida em "Epistemologia naturalizada": "A antiga epistemologia aspirava a conter em si, num certo sentido, a ciência natural; ela a construiria, de algum modo, a partir dos sense data. No seu novo quadro, inversamente, a epistemologia está contida na ciência natural, como um novo capítulo da psicologia. Mas, a seu modo, o antigo envolvimento continua a ser válido. Estudando como são postos os corpos pelo sujeito humano do nosso estudo e como é projetada a sua física a partir dos seus dados, percebemos que nossa situação no mundo é exatamente igual à dele (...) Há assim um envolvimento recíproco, ainda que em sentidos diferentes: 0 da epistemologia na ciência natural e o da ciência natural na epistemologia." (Quine, 1989, p.98-99).

13 Quine, 1989, p. 99.

14 Quine, 1989, p. 99

$150 \mid$ Cad. Nietzsche, Guarulhos/Porto Seguro, v.40, n.2, p. 146-169, maio/agosto, 2019. 
Nietzsche e Quine: da naturalização da estética à epistemologia...

estabelecido em termos de estimulação de receptores sensoriais, caia a consciência onde puder cair" 15 - motivo pelo qual, dir-se-á ainda, são os estímulos de tais receptores "que passam a ser considerados de melhor maneira como a entrada do nosso mecanismo cognitivo." "16 Ao nosso ver, é propriamente em Nietzsche - para quem "nossos órgãos do conhecimento e dos sentidos desenvolveram-se apenas em vista das condições de preservação e crescimento" (Nachlass/ FP 1887, (28) 9 [38], KSA 12.352) - que a remissão da cognição a uma dimensão infra-consciente e naturalizada adquire, com força inédita, uma acepção normativa efetivamente ligada ao subsolo somático da sensorialidade humana, assumindo seus contornos mais explícitos e pregnantes, para fazer jus aqui ao léxico condizente com o terceiro período da obra do filósofo alemão, como processo seletivo de conformação de forças instintivas e pulsionais à base de nossas apreciações estéticas. $\mathrm{O}$ que se deixa ilustrar, por exemplo, mediante um fragmento póstumo de 1887 intitulado, não sem acintosa ironia, Aesthetica:

O que instintivamente nos contradiz do ponto de vista estético é aquilo que, a partir de uma longuíssima experiência, provou ser, ao homem, algo danoso, perigoso, duvidoso: o instinto estético que, então, de imediato, passa a tomar a palavra contém um juízo. Nessa medida, o belo coloca-se no interior da categoria geral dos valores biológicos de proveitoso, benéfico, intensificador de vida [...]. O belo e o feio são, com isso, reconhecidos como condicionados; o mesmo é dizer, em relação aos nossos mais basilares valores de conservação [...]. $O$ belo existe tão pouco como o bom, o verdadeiro. Em suma, trata-se, uma vez mais, de condições de existência de um determinado tipo de homem (Nachlass/FP 1887, (270) 10 [167], KSA 12. 554).

Implicando, não raro, práticas comparativas e hábitos reiterados, transposições figurativas a partir de sensações intensivas,

15 Quine, 1989, p. 99.

16 Quine, 1989, p. 99.

Cad. Nietzsche, Guarulhos/Porto Seguro, v.40, n.2, p. 146-169, maio/agosto, 2019. 
Barros, F. R. M.

assimilações intuitivas de distintos planos e volumes, contornos e nuanças, a tarefa de reconhecimento de qualidades estéticas não é inata e tampouco se resolve numa faculdade disposicional congênita, alheia às condições antropológico-culturais nas quais nos achamos fatalmente abismados. Refletindo adaptações contínuas de nosso aparato perceptivo e desafios a que ele se acha submetido na triagem assídua dos fenômenos que nos condicionam e, a um só tempo, são por nós interpretativamente apreciados, a caracterização de atributos estéticos resultaria, antes do mais, da participação ativa do sujeito da fruição na linha de ação pervasiva de sua própria percepção, razão pela qual não se deixaria explicar como instanciação passiva ou exemplificação de tipos ideais - cuja cognoscibilidade estaria, no fundo, antecipadamente atestada num mundo inteligível de objetos abstratos. Tanto quanto os demais desempenhos sensoriais, a experiência estética albergaria determinados juízos de valor e pressuporia, já de si, uma perspectiva de avaliação tributária de nossas condições de existência e incremento vital. "Tencionar reconhecer um belo ou um feio para além disso", diz-nos Nietzsche, "é um disparate" (Nachlass/FP 1887, (270) 10 [167], KSA 12. 554).

Sem querer adiantar, desde logo, uma definição explicativa para o tipo de relação que se estabeleceria, aqui, entre qualidades estéticas e instâncias supostamente não estéticas - ou, pura e simplesmente, biológicas -, resta que as primeiras seriam, sob tal ótica, condicionadas por valores de conservação, de sorte que esse fator de ordenação parece exigir, em prol de uma ponderação atenta e cuidadosa sobre o legado nietzschiano, uma glosa específica. Pois seria no mínimo temerário querer invocar, aqui, com vistas à descrição desse conjunto de relações, a univocidade e a simetria tradicionalmente legitimadas pelo par causa/efeito, entronizado como nexo necessário e princípio unificador do assim chamado mundo natural. Entendendo causa e efeito à luz de um continuum de forças que se desdobram num fluxo incessante e polimorfo, Nietzsche conta justamente criticar a 
Nietzsche e Quine: da naturalização da estética à epistemologia...

acepção contrafática da condicionalidade tal como esta foi imposta pelas ditas leis naturais. A contrapelo da objetividade apregoada por estas últimas, a causalidade constituiria, a seu ver, um artigo de fé metafísico no sentido de ter sido hipostasiada a partir da admissão, de nossa parte, de uma "intenção" subjacente às próprias coisas. Embalada por projeções antropomórficas, a crença na causalidade teria enraizado-se sob o influxo de um sentimento singular de força e adquirido, mediante extrapolação vivencial, a influência estipulativa de uma convenção elevada à "segunda natureza." "Nossa crença na causalidade," dir-se-á nessa linha interpretativa, "é a crença na força e nos seus efeitos; uma transposição de nossas vivências, por ocasião da qual nós identificamos força e sentimento de força" (Nachlass/FP 1884, 24 [9], KSA 10.647). Em todo caso, a julgar pela dinâmica bifronte do comandar e obedecer que, segundo Nietzsche, regula os processos interpretativos que cruzam e constituem a economia pulsional humana, "condicionar" e "estar condicionado" apontariam, em última análise, para um movimento integrado e envolvente de diferenciações potenciais, ao longo do qual quanta atuantes de força formariam uma hierarquia de mão dupla, segundo a qual uma dada resistência também seria distintiva da própria obediência - e isso precisamente porque vigoraria, no ato mesmo de comando, "o aceite de que a potência absoluta do adversário não foi vencida, assimilada, dissolvida." (Nachlass/FP 1885, 36 [22], KSA 11.561). Assim, seja lá qual for o tipo de consolidação que aqui se queira entrever e classificar, uma qualidade estética não poderia ser, sob tal ângulo, unilateralmente dependente daquilo que a condiciona, já que o próprio condicionamento, no caso, requer que o condicionado não seja completamente dissolvido em termos de sua inerência relacional. Em suma: ainda que haja, em Nietzsche, uma relação condicional entre propriedades estéticas e não estéticas, onde estas últimas figurariam como uma espécie de base ou matéria-prima pulsional a partir da qual nos seria facultado reconhecer as primeiras, seria impertinente 
Barros, F. R. M.

e inclusive equivocado asseverar que tal ligação subsiste como uma relação de dependência parcial e exclusiva.

O indício de que se trata, aqui, de um problema "de fundo", que suplanta o interesse mais pontual sobre o modo pelo qual Nietzsche e Quine caracterizam a sensibilidade artística e a ciência, respectivamente, é a dificuldade que, até hoje, se impõe aos estetas, quando se trata de escapar aos dilemas do realismo e do antirrealismo. Conforme uma versão mais contundente do primeiro, as propriedades estéticas independeriam, em termos de sua recognição, de outras espécies de propriedades e estariam aí, à disposição, para ser detectadas e descritas. ${ }^{17}$ De acordo com o segundo, as ditas qualidades estéticas simplesmente não existiriam, sendo que "um mundo nãoestético não apenas seria possível, senão que facilmente imaginável, e isso justamente por ser ele idêntico ao nosso mundo real." ${ }^{18} \mathrm{Em}$ tal contexto, a multiplicação de hipóteses de interpretação faria o "cortiço de possíveis do sr. $Y " 19$ parecer um loft simples e funcional. Recorre-se amiúde, no esforço de descortinar um horizonte realista menos rígido, à noção de superveniência. Dir-se-ia, aqui, para lembrar a formulação de Jerrold Levinson, que dois “objetos (isto é, duas obras de arte) que diferem esteticamente têm também, necessariamente, de diferir não-esteticamente [quer dizer, não poderia haver dois objetos que fossem esteticamente diferentes e, ainda assim, não-esteticamente idênticos]. ${ }^{.20}$ Importa supor, nesse patamar reflexivo, que propriedades de um tipo $\mathrm{X}$ são supervenientes em relação às propriedades de um outro tipo Z, quando as coisas são X em função de serem Z, de modo que não poderia haver um alteração substantiva em $\mathrm{X}$ sem uma mudança concomitante em Z. Como se explorássemos minas

17 A esse respeito, cf. o conhecido texto de Philip Pettit "The possibility of aesthetic realism", 2004, pp.158-171)

18 Maria E. Reicher, 2005, p. 61.

19 Quine, 2011, p.15.

20 Jerrold Levinson, 1984, p.93.

154| Cad. Nietzsche, Guarulhos/Porto Seguro, v.40, n.2, p. 146-169, maio/agosto, 2019. 
Nietzsche e Quine: da naturalização da estética à epistemologia...

isoladamente desobstruídas e, ao mesmo tempo, comunicantes, seria plausível dizer, por exemplo, que as propriedades ditas psicológicas são supervenientes às propriedades biológicas e estas, por seu turno, às propriedades químicas e assim por diante. Entre outras, uma relevante consequência dessa concepção à caracterização estética é o fato de que, se, por um lado, objetos com diferentes qualidades estéticas possuem diferentes qualidades não-estéticas, por outro, “objetos com os mesmos atributos estéticos não necessariamente possuem os mesmos atributos não-estéticos."21

É curto o caminho que vai da superveniência à noção mais tradicional de fundamentação, sendo que, aqui, o potencial perigo estaria na tentação de inferir, a partir de uma suposta prerrogativa ontológica dos atributos não-estéticos em relação às assim chamadas qualidades estéticas, que os objetos pudessem manter autarquicamente os primeiros e abrir mão, sem mais nem menos, destas últimas - como se o mundo "em si" não fosse constitutivamente estético, ou, então, assim o fosse, mas de um modo que não nos seria facultado apreendê-lo. É certo que, sob uma dada perspectiva, tanto a visão de conjunto advogada pelo Sr. Wyman quanto os valores biológicos de conservação aludidos pelo filósofo alemão poderiam ser considerados como simples "portadores" de qualidades estéticas. Mas é correto ainda que, ao recorrerem a tais designações, Nietzsche e Quine não se fiam numa dimensão impenetravelmente profunda ou enigmaticamente confidencial da sensibilidade. Fazendo intervir termos como "senso estético" e "belo", os dois acreditam operar com características que não carecem, para adquirir valoração, de uma faculdade especial pela qual o gosto seria ajuizado, ou, então, de um sentimento puro e esotérico mediante o qual o estético seria reflexivamente legitimado. Para ambos, ainda que diferentemente, o ponto de partida para apreciar e discernir referências estéticas ou noções mais sutis também inclui nosso envolvimento constitutivo

21 Maria E. Reicher, 2005, p.61. 
Barros, F. R. M.

com propriedades naturais não-estéticas, sendo que seria um equívoco considerar esta última instância como um estofo sensitivo completamente à parte, qual uma condição prévia e suficiente para consolidar, de forma monocausal e unidirecional, representações figurativas ulteriores e, em certa medida, "desnaturadas". ̀̀ força de resguardar a sobriedade e austeridade em coisas do espírito, termina-se, às vezes, em nome dos próprios excessos, por alimentar açodadamente ímpetos sensualistas ingênuos e idealistas, cedendo terreno a argumentos analógicos metafisicamente atraentes, tal como aquele que faz ombrear, num paralelismo sedutor, a relação entre propriedades sensíveis e sensações sensíveis (entre uma dada cor, por exemplo, e sua correspondente intuição particular) e o vínculo entre qualidades estéticas e intensividades subjetivas - fazendo-nos crer que esta última ligação se consolida do mesmo modo que a primeira, preservando a positividade alegadamente inerente aos chamados dados sensíveis elementares. ${ }^{22}$ A cor verde dos prados por certo não é uma mera ilusão, no sentido em que, ao se nos aparecer, dela percebemos apenas uma aparência quimérica. Mas, convenhamos, as partículas elementares da grama - se formada por corpúsculos atômicos ou nebulosos estados da matéria, pouco importa - não cheiram à grama, com seu odor balsâmico e orvalhado. Permanecendo a "objetividade", como bem nos lembra Rubens Rodrigues Torres Filho, "a condição para haver "objeto", ${ }^{23}$ o verde refere-se, com efeito, à sensação objetiva, mas cumpre atribuir sua agradabilidade “à sensação subjetiva, pela qual nenhum objeto é representado." ${ }^{24} \mathrm{~A}$ dificuldade consiste justamente em examinar e expor essa sensação subjetiva sob uma ótica naturalista menos reducionista e confinante,

22 No que se refere à descrição desse argumento, seguimos aqui a exposição de Maria Reicher, a qual nos conduz à seguinte conclusão: "Conforme o argumento da analogia, as qualidades valorativas estéticas são tão objetivas quanto as qualidades sensíveis.” (Maria E. Reicher, 2005, p.76)

23 Rubens Rodrigues Torres Filho, 2004, p.43.

24. Immanuel Kant, 1984, p. 211.

156 | Cad. Nietzsche, Guarulhos/Porto Seguro, v.40, n.2, p. 146-169, maio/agosto, 2019. 
Nietzsche e Quine: da naturalização da estética à epistemologia...

que rechaça modalidades de interpretação extra-naturais e extramundanas, mas sem reeditar, ao modo mecanicista e objetivista, uma noção de sensorialidade fundada numa significação positivista do mundo. Vejamos, então, ainda que em linhas gerais, como Nietzsche e Quine combatem, ou, ao menos, se inoculam contra esse risco.

II.

Em seu livro Nietzsche's Naturalism: Philosophy and Life Sciences in the Nineteenth Century, Christian J. Endem, reconhecendo características que tornariam o naturalismo metodológico de Quine preferível a versões substancialmente mais ortodoxas e, afinal de contas, menos interessantes de naturalismo, escreve: "Nietzsche teria endossado, sem dúvida, a visão de Quine segundo a qual as postulações da ciência são simplesmente mais eficazes que aquelas feitas pelo mito e pela religião: a força normativa dos enunciados sobre fotossíntese, por exemplo, são mais vinculativos que a ideia de que foram as divindades homéricas ou o Deus judaico-cristão os responsáveis pela criação do ar que respiramos. ${ }^{" 25}$ Sem dúvida, seria possível encontrar inegáveis semelhanças entre ambos os autores em que pese as diferenças, igualmente inegáveis, por exemplo, no que concerne à unidade da ciência haurida de uma uniformidade à base dos métodos científicos [no caso de Quine]. Que se considere, por exemplo, os dois dogmas do empirismo combatidos por Quine em seu célebre e homônimo ensaio. Sobretudo o primeiro, relativo à distinção entre analítico e sintético: verdades que seriam verdadeiras em virtude de seu sentido - "nenhum solteiro é casado" - e verdades que seriam verdadeiras em virtude, digamos, dos "fatos". $\mathrm{O}$ argumento contido em "Dois dogmas do empirismo" fia-se na ideia de que a analiticidade pressupõe a sinonímia e, portanto, própria analiticidade, trazendo consigo, como exigência de compreensibilidade, noções e

25 Christian J. Endem, 2014, p.61.

Cad. Nietzsche, Guarulhos/Porto Seguro, v.40, n.2, p. 146-169, maio/agosto, 2019. 
Barros, F. R. M.

entimemas que já lhe assegurariam uma validade $a b$ ovo. Seriam elas as noções de definição, intersubstitutibilidade e regra semântica. Essa caracterização tripartite da analiticidade incidirá, sobretudo, na analiticidade relativa às verdades semânticas - e não tanto nas verdades ditas lógicas -, mas isso justamente no intuito de mostrar que, pela sinonímia, seria possível migrar da classe de sentenças analíticas semanticamente verdadeiras para a classe de sentenças logicamente válidas. ${ }^{26}$ Substituindo, por exemplo, "solteiro" por "não casado". Aliás, é justamente isso o que estaria efetivamente em jogo, segundo Quine, no uso analítico da noção de definição: “Como descobrimos que 'solteiro' é definido como 'homem não casado'? Quem o definiu assim, e quando? Devemos recorrer ao dicionário mais próximo e aceitar a formulação do lexicógrafo como uma lei? (...) O lexicógrafo é um cientista empírico, cuja ocupação é registrar fatos passados; e se ele registra 'solteiro' como 'homem não casado' é, graças à sua crença de que há uma relação de sinonímia entre essas formas, implícita no uso geral ou preponderante, anterior a seu trabalho." ${ }^{97}$

É bem provável que o autor de Sobre verdade e mentira no sentido extra-moral se colocasse de acordo com essa compreensão. Como ele mesmo dirá: “Quando alguém esconde algo detrás de um arbusto, volta a procurá-lo justamente lá onde o escondeu e além de tudo o encontra, não há muito do que se vangloriar nesse procurar e encontrar (...) Se crio a definição de animal mamífero e, aí então, após inspecionar um camelo, declaro: veja, eis um animal mamífero, com isso, uma verdade decerto é trazida à plena luz, mas ela possui um valor limitado, digo, ela é antropomórfica de fio a pavio e não contém um único ponto que fosse "verdadeiro em si"" (WL/VM 1, KSA 1.883). E talvez Nietzsche também aquiescesse, sem muita dificuldade, com a crítica de Quine ao segundo dogma do

26 Seguimos aqui, na elucidação desse ponto, a interpretação de Peter Faulstich, 2002.

27 Willard Van Orman Quine, 2011, p.43

158 Cad. Nietzsche, Guarulhos/Porto Seguro, v.40, n.2, p. 146-169, maio/agosto, 2019. 
Nietzsche e Quine: da naturalização da estética à epistemologia...

empirismo, qual seja, o relativo ao reducionismo fenomenal: a crença de que cada enunciado significativo é equivalente a alguma coisa com base na experiência imediata. Haurida de uma separação entre a sensação experimentada e o som emitido pelo falante, a palavra designaria, para o filósofo alemão, apenas uma relação figurada entre as coisas e nós mesmos, e jamais se referindo às próprias coisas. Duplamente metafórica, o processo de formação de nossos vocábulos comportaria uma transposição bem pouco objetiva: uma excitação nervosa convertida numa imagem mental e, em seguida, a transposição de tal imagem num som articulado. ${ }^{28}$ Heteróclito, o deslocamento operaria com elementos que dizem respeito a esferas disjuntivas, de modo que uma correspondência sintética entre coisas e enunciados só poderia ser obtida pela suspensão, via identificação metonímica, entre o conceito derivado da sensação intensiva e o juízo balbuciado. "O juízo sintético", afirma Nietzsche a propósito, "descreve uma coisa de acordo com suas consequências, isto é, essência e consequência são identificadas (...) O conceito 'lápis' é trocado pela 'coisa' lápis. $\mathrm{O}$ ‘é' contido no juízo sintético é falso, encerra uma transposição por meio da qual duas esferas distintas são colocadas lada a lado, sendo que entre ambas jamais pode dar-se uma igualação." (Nachlass/FP 1872/1873, 19 [242], KSA 7.495).

28 Tal como dirá Nietzsche, nesse mesmo contexto, numa de suas mais conhecidas passagens: "A 'coisa em si' (ela seria precisamente a pura verdade sem quaisquer consequências) também é, para o criador da linguagem, algo totalmente inapreensível e pelo qual nem de longe vale a pena esforçar-se. Ele designa apenas as relações das coisas com os homens e, para expressá-las, serve-se da ajuda das mais ousadas metáforas. De antemão, um estímulo nervoso transposto em uma imagem! Primeira metáfora. A imagem, por seu turno, remodelada num som! Segunda metáfora" (WL/VM 1, KSA 1.879). Não deixa de ser curioso notar, à laia de comparação especulativa, que Quine mesmo tratará de entrever, no processo de formação do signo linguístico, um derradeiro estímulo nervoso, mas, desta feita, gerado pelo próprio balbucio do falando. Acerca deste que considera ser um "pecado original", o pensador estadunidense dirá: "Há, em verdade, um precedente arcaico para a confusão de signo e objeto; o condicionamento primitivo do balbucio da criança é ambíguo nesse ponto. Pois suponhamos um bebê recompensado por lhe ter acontecido balbuciar algo como mamãe ou água precisamente quando apareceu a mãe ou a água. Os estímulos que são assim reforçados são obrigatoriamente dois: há não somente a aparição do objeto, há igualmente a própria palavra, ouvida pela criança de seus próprios lábios. A confusão de signo e objeto é um pecado original, contemporâneo da palavra." (Willard Van Orman Quine, 1989, p.59). 
Barros, F. R. M.

No fundo, seria fútil procurar um limite entre enunciados analíticos, válidos aconteça o que acontecer, e enunciados sintéticos, validados pelas “coisas". Qualquer enunciado pode ser considerado verdadeiro, aconteça o que acontecer, se fizermos ajustes drásticos o bastante em alguma parte de nosso sistema discursivo de conhecimento. Como dirá Quine a esse respeito, numa conhecida passagem: "Mesmo um enunciado muito próximo da periferia pode ser considerado verdadeiro diante de uma experiência recalcitrante, alegando-se alucinação ou modificando-se certos enunciados que chamamos de leis lógicas. Inversamente, pela mesma razão, nenhum enunciado está imune à revisão. ${ }^{929} \mathrm{E}$ a partir disso talvez fosse possível estabelecer outras proximidades entre os dois autores senão de berço, ao menos, em intenção. Se para Quine, afinal, não se trata de traduzir atomicamente as sentenças sobre o mundo em termos de sense data ou de observação, mas de abandonar as formas redutivas e enunciados empíricos isolados em favor de uma visão de conjunto $;^{30} \mathrm{ou}$, então, para trazer à tona o tema da tradução, que lhe era bastante caro, se as sentenças inglesas de uma teoria só têm significado quando tomadas em conjunto como um corpo, de sorte que só quando tomadas em conjunto poderiam "justificar sua tradução para o arunta", ${ }^{31}$ não havendo justificativa para um emparelhamento de sentenças inglesas componentes com sentenças componentes do arunta "a não ser a de que essas correlações fazem com que resulte

29 Willard Van Orman Quine, 2011, p. 67.

30 Cf., nesse mesmo contexto de um empirismo "sem dogmas", a seguinte descrição englobante: "A totalidade de nossos assim chamados conhecimento e crenças das mais casuais questões de Geografia e História até as mais profundas leis da Física atômica ou mesmo da Matemática pura e da Lógica, é um tecido feito pelo homem, que encontra a experiência apenas nas extremidades. Ou, mudando a imagem, a totalidade da ciência é como um campo de força, cujas condições limítrofes são a experiência. Um conflito com a experiência na periferia ocasiona reajustes no interior do campo. Os valores de verdade têm de ser redistribuídos em alguns de nossos enunciados. A reavaliação de alguns enunciados acarreta a reavaliação de outros, em função de suas interconexões lógicas" (Willard Van Orman Quine, 2011, 66-67).

31 Willard Van Orman Quine, 1989, p. 97.

$160 \mid$ Cad. Nietzsche, Guarulhos/Porto Seguro, v.40, n.2, p. 146-169, maio/agosto, 2019. 
Nietzsche e Quine: da naturalização da estética à epistemologia...

correta a tradução da teoria como um todo", 32 comportar-se como se comportaria um empirista "dogmático" equivaleria, aqui, a ler e traduzir o "texto" do mundo tal como, em termos nietzschianos, o décandént lítero-musical lê e traduz os textos que se lhe oferecem, nos quais "a palavra se torna soberana e pula para fora da frase, a frase extravasa e obscurece o sentido da página, a página ganha vida às custas do todo - o todo não é mais um todo. (...) toda vez, anarquia dos átomos, desagregação da vontade." (WA/CW 7, KSA 6.27). E se, para Quine, o saldo de implicações empíricas numa tradução não se reduz a tal emparelhamento, é de esperar que muitas maneiras diferentes de traduzir as sentenças componentes, cada uma delas diferente da outra, ofereçam implicações para a teoria como um todo. Precisamente nessa direção, dirá ele: "não pode haver razão para dizer qual de duas traduções claramente dessemelhantes está correta."33 Isso porque, talvez lhe dissesse Nietzsche, para haver comunicação significativa, não basta lançar mão das mesmas palavras ou dos mesmos sinais sonoros para os mesmos construtos conceituais; é preciso "empregar as mesmas palavras igualmente para o mesmo gênero de vivências internas, é necessário, por fim, ter sua experiência comum com o outro"(JGB/BM 268, KSA5.221). E tampouco a tradução sairá incólume, digamos, dessa exigência de comunhão vivencial. Não por acaso, evocando uma imagem de cunho fisiológico, sublinha ainda o autor d'Além de bem e mal: "O que menos se deixa traduzir de uma língua à outra é o tempo de seu estilo: o qual tem seu fundamento (...) no tempo-médio de seu 'metabolismo', dito fisiologicamente" (JGB/BM 28, KSA 5.46). Uma boa tradução estaria aí para indicar que, condicionadas por poderosas correntes de energia pulsional, incluindo o tempo de tensão de tal energia, palavras de diferentes línguas poderiam remeter a vivências e condições de existência similares, deixando-se imantar, a título de signos imagéticos, a

32 Willard Van Orman Quine, 1989, p.97.

33 Willard Van Orman Quine, 1989, p.97.

Cad. Nietzsche, Guarulhos/Porto Seguro, v.40, n.2, p. 146-169, maio/agosto, 2019. 
Barros, F. R. M.

grupos de sensações reciprocamente assimiláveis. E, por essa senda, retomamos o problema da consolidação dos atributos estéticos a partir de instâncias aparentemente não-estéticas. Num revelador e emblemático fragmento póstumo de 1882, Nietzsche descreve aquilo que, a seu ver, acha-se efetivamente em jogo quando nos colocamos a escrever: "Na verdade, o que há de mais compreensível na linguagem não é a palavra mesma, mas o som, a força, a modulação, o tempo com os quais uma sequência de palavras é dita - enfim, a música por detrás das palavras, a afetividade por detrás desta música, a pessoa por detrás de tal afetividade: tudo aquilo que, portanto, não pode ser escrito" (Nachlass/FP 1882, 3 [1] 296, KSA 10.89). À luz dessa confluência, a tradução de um texto deve buscar comportar, em sua própria articulação enunciativa, aquilo que é originalmente haurido de um plano expressivo e subjetivamente singular, transferido e preservado pela tonalidade discursiva que, enquanto vetor "musical", ecoa e multiplica, ainda que de forma delimitada, uma intensividade escalonada de sensações, ou, como dirá Nietzsche, por "uma multiplicidade de pessoas." Verter um escrito noutro apenas em função de sua textualidade e seu conteúdo figurativo proposicional implicaria, assim, não somente um descompasso entre o vernáculo e a sentença que se lhe seria compatível noutra língua, senão que entre as palavras e a própria afetividade. Incongruência, diga-se de passagem, que ameaça outras formas de "tradução", mais pessoais e, portanto, tanto menos textuais: "Mesmo em toda amizade ou caso amoroso isso é colocado à prova: nenhum deles tem durabilidade, tão logo se torna patente que, valendo-se das mesmas palavras, um dos dois sente, tenciona, adivinha, deseja e teme diferentemente do outro" (JGB/BM 268, KSA 5.222).

Subsumir e interpretar essa multiplicidade pulsional e afetiva a partir de uma relação simétrica e unilateral de superveniência acarreta, entre outras coisas, enfeixá-la numa relação de dependência aos moldes de uma causalidade estruturalmente igual àquela que 
Nietzsche e Quine: da naturalização da estética à epistemologia...

preside as leis mecânicas, irmanando a ponderação "bio-estética" de Nietzsche ao tipo de cientificismo que lhe é mais avesso, àquela interpretação que, como ele mesmo dirá, é "uma das mais estúpidas, quer dizer, mais carentes de sentido dentre todas as possíveis interpretações-de-mundo: isso dito ao ouvido e à consciência dos senhores mecanicistas, que hoje em dia apreciam andar entre os filósofos e acreditam piamente que a mecânica é doutrina das leis primeiras e últimas, sobre as quais a inteira existência deveria estar edificada, como que sobre uma só fundação." (FW/GC 373, KSA 3.626). E isso, ao que tudo indica, ontem e hoje. Pois talvez não seja, afinal de contas, completamente sem razão que Richard Schacht, por exemplo, em seu seminal ensaio sobre "O naturalismo de Nietzsche", critique Brian Leiter por este incluir o naturalismo praticado pelo scientian nietzschiano no rol de um naturalismo polido no esmeril do determinismo cientificista. ${ }^{34} \mathrm{E}$ há motivos

34 Ainda que fundamental para a constituição de nossos pontos teóricos de sustentação, a restituição dos argumentos que cruzam e dividem o aludido ensaio de Richard Schacht suplantaria em muito os limites dessa nossa, no fim de contas, panorâmica e comparativa exposição. Em todo caso, à laia de ilustração, convém exibi-los de modo condensado: "Alguns intérpretes de Nietzsche em anos recentes tomaram-no não apenas como um naturalista filosófico do gênero amplamente 'scientian' [instruído], mas como um naturalista cientificista. Brian Leiter é um caso típico. Em termos básicos, estou de acordo com a afirmação de Leiter, no início de seu Nietzsche on morality, segundo a qual Nietzsche pertence 'à companhia de naturalistas como Hume e Freud - isto é, grosso modo ele está entre os filósofos da natureza humana'. Mas então começam meus problemas com sua restituição do naturalismo de Nietzsche. Leiter estrutura sua discussão de Nietzsche a partir da 'distinção entre duas doutrinas naturalistas básicas: metodológica (ou M-naturalismo) e substantiva (ou S-naturalismo)'. Ele caracteriza a 'doutrina metodológica' como a convicção de que 'a pesquisa filosófica deve ser contínua em relação à pesquisa nas ciências' - isto é, 'contínua em relação às ciências tanto em virtude de sua dependência dos resultados efetivos do método científico em diferentes domínios quanto em virtude do emprego e da imitação de modos especificamente científicos de ver e explicar as coisas'. Com esta última frase Leiter quer dizer: ver tudo o que acontece no mundo - incluída a vida humana - como fenômenos com 'causas deterministas' semelhantes às que figuram em teorias e explicações científicas. 'O principal da atividade filosófica [de Nietzsche]', ele sustenta, foi 'dedicado a variações no projeto naturalista' e à 'explicação naturalista' de diversos fenômenos humanos 'que é contínua tanto em relação aos resultados quanto aos métodos das ciências'. Leiter considera que isso torna Nietzsche um 'naturalista metodológico' no sentido precisado. Ele considera ainda que Nietzsche é o que chama de 'M-naturalista especulativo' assim como Hume, que (diz Leiter) 'constrói uma teoria especulativa da natureza humana... modelada sobre o paradigma científico mais influente na época'. De acordo com Leiter, isto é exatamente o que Nietzsche também fez - e é assim que seu naturalismo deve ser entendido. (...) Eu diria que isso é um exemplo paradigmático da interpretação 
Barros, F. R. M.

suficientes para tanto. Considere-se, enfim, como Nietzsche mesmo dirá, "que o valor de uma música fosse valorativamente apreciado conforme o quanto dela fosse possível contar, computar, converter em fórmulas - quão absurda seria uma tal apreciação valorativa ‘científica' da música! O que dela teríamos captado, compreendido, conhecido? Nada, justamente nada daquilo que, nela, constitui propriamente música!..." (FW/GC 373, KSA 3.626). A questão é que, quando refletidas sobre o movente pano de fundo da fisiopsicologia nietzschiana, onde as produções humanas são interpretadas como sintomas das configurações pulsionais que regulam nossas funções corpóreas basilares, ${ }^{35}$ tanto o conceito de arte como a noção de natureza incluiriam muito mais aspectos do que normalmente se crê. O próprio âmbito que designa o orgânico surgirá como produto de um processo criativo de interpretação, apto a engendrar, como que num movimento crescente de especificidades, novas injunções interpretativas. A "capacidade de criar (dar forma, fantasiar, inventar)" (Nachlass/FP 1885, 34 [247], KSA 11.503) seria uma competência fundamental ínsita às próprias funções orgânicas, as quais, agindo e reagindo em função da posição que exercem na multiplicidade de forças que as constituem, seguiriam o sentido intrínseco a seu próprio interpretar - "na formação de um órgão," dir-se-á, sob tal ângulo, "trata-se de uma interpretação (...) O processo orgânico pressupõe um contínuo interpretar" (Nachlass/FP 1885/1886, 2 148, KSA 12.140). Também no nível da sensorialidade essa atividade crucial se daria a conhecer à medida que nosso aparato perceptivo é chamado a desempenhar seu papel projetivo e delimitador. Assim como nosso

cientificista do naturalismo de Nietzsche. Eu de minha parte concebo o seu naturalismo de um modo bastante diferente: como algo que não apenas se coloca, mas inclusive pretende se colocar exatamente como uma alternativa - e até mesmo como um antídoto - a esse tipo de naturalismo (cientificista)" (Richard Schacht, 2011, p. 40-42).

35 A respeito de uma definição explicativa e do emprego propriamente nietzschiano do termo "fisiologia", cf. o verbete Fisiopsicologia (Physio-Psychologie), elaborado por Wilson Antonio Frezzatti Jr., no Dicionário Nietzsche (MARTON, Scarlett [ed.]. São Paulo: Edições Loyola/GEN, 2016, pp.236-238).

164| Cad. Nietzsche, Guarulhos/Porto Seguro, v.40, n.2, p. 146-169, maio/agosto, 2019. 
Nietzsche e Quine: da naturalização da estética à epistemologia...

olho não se limitaria a refletir, qual um espelho, aquilo que o estímulo retínico suscita, a membrana timpânica tampouco se contentaria em captar passivamente os sons formados pela vibração do ar, senão que, limitada ao grau humano de percepção sonora, associaria os golpes que a fazem vibrar, transpondo e traduzindo, centrífuga e inventivamente, a grandeza intensiva que lhe estimula - estando antecipadamente fora de questão uma escuta "objetiva", ou, para lembrar um lapidar fragmento de juventude, "ouvimos o som apenas em nós - supor, a partir daí, que exista um mundo exterior implica, já, outro passo" (1872/1873, 19 [217], KSA 7.487). Algo análogo ocorreria com a esfera que designa a sucessão sonora, isto é, o ritmo mesmo. "O ser humano", lê-se a esse respeito ainda, "é uma criatura formadora-de-ritmos. Ele introduz todos os acontecimentos em tais ritmos, trata-se de uma maneira de se apoderar das "impressões" (Nachlass/FP 1883/1884, 24 [14], KSA 10.651). Nesse sentido, supor uma concatenação sonora "pura" e sem prévia decomposição rítmica do vivente que sente e pulsa, tal como apregoa o mecanicismo equivaleria, no limite, a um nada perceptivo, à denegação mesma da efetividade auditiva, um "princípio destruidor, inimigo da vida" (FW/ GC 344, KSA 3.576). E aqui vale lembrar o comentário certeiro de Günter Abel a esse propósito: "Os seres vivos poderiam viver sem o conhecimento da lógica formal e sem as obras de arte no sentido mais estreito. Mas, sem o lógico e sem o artístico, não são capazes de sobreviver." 36

Inserido nesse quadro expositivo mais visceral, o estético pressupõe uma espécie de saber-fazer instintivamente aprendido e ensinado, dedicado a selecionar e assimilar, apreciar e separar, conformar e negligenciar impulsos em proveito da organização "artistística", por assim dizer, das forças que delimitam e condicionam nossa capacidade de interpretar o mundo de acordo com o modo como somos afetados nas relações que com ele estabelecemos. E como

36 G. Abel, 1987, p. 116.

Cad. Nietzsche, Guarulhos/Porto Seguro, v.40, n.2, p. 146-169, maio/agosto, 2019. 
Barros, F. R. M.

não detectar, nesse sensualismo plástico e inventivo, uma versão mais originária e recuada do modus operandi de que se vale o sagaz compositor musical, que dissimula, com elevado grau de controle criativo, a dinâmica de algumas cadências, encobrindo e sombreando algumas notas em favor de outras, de sorte a favorecer a ênfase ou a iluminação de sonoridades mais relevantes para a execução de sua peça? Em verdade, consideradas as devidas diferenças e concedida a parte à extrapolação comparativa, poder-se-ia dizer que, seja em coisas de música, seja na esfera das funções orgânicas, a fantasia do artista "produz incessantemente coisas boas, medianas e ruins, mas sua faculdade de julgar [Urtheilskraft], altamente treinada e afiada, rechaça, escolhe, reúne; tal como se entrevê, hoje, nos livros de anotação de Beethoven, que combinou pouco a pouco as mais majestosas melodias (...) Todos os grandes foram grandes trabalhadores, incansáveis não somente no inventar, senão que também no rechaçar, selecionar, reconfigurar e ordenar" (MA I/HH I 155, KSA 2.147).

Não haveria, em rigor, obra de arte musical sem uma dada decomposição seletiva e interpretativa do próprio material sonoro. Se tomamos por certa e gratuita a naturalidade das escalas de sons "naturais" é porque sua escuta sedimentou-se, em nós, seres naturais conformados à normatividade, como um padrão auditivo. Pelo uso frequente de suas fórmulas, a teoria musical esqueceu-se de sua própria arbitrariedade distintiva. Concedendo aos sons uma única função estrutural, neles gravada desde o despertar da tonalidade, considerou-os irrefletidamente como signos sonoros eternos, sem data de fabricação ou validade. É justamente essa invariância irrefletida que tornaria tão difícil, à consciência historicamente sedimentada, o abandono da tonalidade, assim como, noutro registro, a renúncia aos artigos de fé do cientificismo. Pois também o cientista não retira seus pressupostos de uma cartola mágica e tampouco estes lhe caem diretamente do céu, razão pela qual a própria ciência - e Quine não

$166 \mid$ Cad. Nietzsche, Guarulhos/Porto Seguro, v.40, n.2, p. 146-169, maio/agosto, 2019. 
Nietzsche e Quine: da naturalização da estética à epistemologia...

se cansará de insistir nesse ponto -, precisa começar sempre in media res ${ }^{37}$ a partir do já urdido e testado tecido feito pelos seres humanos, demasiado humanos. Daí, não por acaso, a exortação contida na "Epistemologia naturalizada": "Estamos em busca de uma compreensão da ciência enquanto instituição ou processo no mundo, e não pretendemos que essa compreensão seja melhor do que a ciência que é seu objeto." ${ }^{38}$ A circularidade ou substituição de tarefas entre ciência, epistemologia, psicologia, fisiologia e arte ${ }^{39}$ só pode incomodar aquele que, querendo-se um herdeiro visado pelo ideal de proposições puras e linguisticamente neutras, acredita poder começar do nada, sem nenhum comprometimento com qualquer teoria ou parti pris rudimentar, como se não fosse, também ele, um organismo adaptativo capaz de "ver a ciência sob a ótica do artista, mas a arte sob a ótica da vida..." (GT/NT, Tentativa de autocrítica 2, KSA 1.14).

37 Empregamos aqui essa expressão na acepção que lhe foi atribuída por Paul A. Gregory no terceiro capítulo de seu livro Quine's Naturalism. Language, Theory, and the Knowing Subjetc (Londres/ Nova York, Bloomsbury, 2008), que se intitula "Language, Theory, and beginning In Mediis Rebus". 38 Willard Van Orman Quine, 1989, p.99.

39 Defendendo-se do argumento da circularidade, Quine dirá: "A transferência das responsabilidades epistemológicas para a psicologia havia sido condenada, anteriormente, como um raciocínio circular. Se o objetivo do epistemólogo era o de validar os fundamentos da ciência empírica, ao empregar a psicologia ou outra ciência empírica nessa avaliação, ele estaria frustrando seus propósitos. Todavia, tais escrúpulos contra a circularidade terão pouco relevância, uma vez que tivermos parado de sonhar com uma dedução da ciência a partir de observações." (Willard Van Orman Quine, 1989, p.94). 
Barros, F. R. M.

\section{Nietzsche and Quine: From the Naturalization of Aesthetics to Naturalized Epistemology}

Abstract: Far from intending to exhaust all the possible similarities between Nietzsche and Quine, the following text aims at showing, through paradigmatic comparisons and admissible methodological convergences, how both authors - by making naturalistic assumptions to interpret knowledge and aesthetics respectively - allow us to think of a less confining and more creative naturalism, free from the prejudices of scientism and more compatible with the artistic sensibility in general.

Keywords: Nietzsche, Quine, aesthetics, knowledge, supervenience, naturalism.

\section{Referências bibliográficas}

ABEL, G. Logik und Ästhetik. In: Nietzsche-Studien. Berlim/Nova York: de Gruyter, n.16, 1987, pp. 112-148.

ENDEM, Christian J. Nietzsche's Naturalism: Philosophy and Life Sciences in the Nineteenth Century. Cambridge: Cambridge University Press, 2014.

FAULSTICH, Peter. In welchem Verhältnis stehen für Quine die Begriffe Synonymie und Analytizität? Munique: GRIN Verlag, 2002.

GREGORY, Paul A. Quine's Naturalism. Language, Theory, and the Knowing Subjetc. Londres/Nova York: Bloomsbury, 2008.

HUME, David. Do padrão do gosto. Tradução de Luciano Trigo. In: DUARTE, Rodrigo (org.). O belo autônomo. Belo Horizonte: Autêntica/Crisálida, 2012, pp. 91-113.

KANT, Immanuel. Textos selecionados. Tradução de Rubens Rodrigues Torres Filho. São Paulo: Abril Cultural, 1984.

LEVINSON, Jerrold. Aesthetic Supervenience. In: The Southern Journal of Philosophy, n. 22, 1984, pp. 93-110.

$168 \mid$ Cad. Nietzsche, Guarulhos/Porto Seguro, v.40, n.2, p. 146-169, maio/agosto, 2019. 
Nietzsche e Quine: da naturalização da estética à epistemologia...

MARTON, Scarlett (org.). Dicionário Nietzsche. São Paulo: Edições Loyola, 2016.

NIETZSCHE, Friedrich. Sämtliche Werke. Kritische Studienausgabe (KSA). Berlim/ Nova York: Walter de Gruyter, 1999.

PETTIT, Philip. The possibility of aesthetic realism. In: LAMARQUE, Peter; OLSEN, Stein Haugom (org.). Aesthetics and the Philosophy of Art - The Analytic Tradition. Oxford: Blackwell Publishing, 2004, pp.158-171.

QUINE, Willard Van Orman. De um ponto de vista lógico. Tradução de Antonio Ianni Segatto. São Paulo: Editora Unesp, 2011.

. Relatividade ontológica e outros ensaios. In: Os pensadores. São Paulo: Nova Cultural, 1989.

REICHER, Maria E. Einführung in die philosophische Ästhetik. Darmstadt: Wissenschaftliche Buchgesellschaft, 2005.

SCHACHT, Richard. O naturalismo de Nietzsche. Tradução de Olímpio Pimenta. In: Cadernos Nietzsche. São Paulo, 2011, n. 29, pp.35-75.

TORRES FILHO, Rubens Rodrigues. Ensaios de filosofia ilustrada. São Paulo: Iluminuras, 2004.

Recebido em 10/05/2019

Aceito em 15/06/2019 